\title{
Aesthetic result after breast-conserving therapy is associated with quality of life several years after treatment. Swedish women evaluated with BCCT.core and BREAST- $Q^{\text {TM }}$
}

\author{
Cecilia Dahlbäck ${ }^{1,2}$ ( Jenny Heiman Ullmark ${ }^{3,4} \cdot$ Martin Rehn $^{1,2} \cdot$ \\ Anita Ringberg ${ }^{2,5} \cdot$ Jonas Manjer $^{1,2}$
}

Received: 13 April 2017/ Accepted: 17 May 2017/Published online: 23 May 2017

(c) The Author(s) 2017. This article is an open access publication

\begin{abstract}
Purpose A gold standard for evaluation of aesthetic outcome after breast-conserving therapy (BCT) is still lacking. The BCCT.core software has been developed to assess aesthetic result in a standardised way. We aimed to study how the result of BCCT.core after BCT is associated with quality of life, measured with the BREAST-Q ${ }^{\mathrm{TM}}$, a validated questionnaire.

Methods Women eligible for BCT were consecutively recruited between February 1st 2008 and January 31st 2012 $(n=653)$. Photographs of 310 women, taken one year after BCT, were evaluated using the BCCT.core software. The postoperative BCT module of the BREAST- $\mathrm{Q}^{\mathrm{TM}}$ questionnaire was administered by mail and 348 questionnaires were returned (median 5.5 years after BCT). In all, 216 women had both BCCT.core results and completed BREAST-Q ${ }^{\mathrm{TM}}$ questionnaires available.

Results The results from the BCCT.core evaluation were: excellent $n=49$ (15.8\%); good $n=178$ (57.4\%); fair $n=73$ (23.5\%); poor $n=10$ (3.2\%). The median BREAST-Q ${ }^{\mathrm{TM}}$ score for satisfaction with breasts was 66
\end{abstract}

Cecilia Dahlbäck

cecilia.dahlback@med.lu.se

1 Department of Surgery, Skåne University Hospital, Malmö, Sweden

2 Department of Clinical Sciences, Malmö, Lund University, Lund, Sweden

3 Department of Surgery, Sahlgrenska University Hospital, Gothenburg, Sweden

4 Institute of Clinical Sciences, Sahlgrenska Academy at the University of Gothenburg, Gothenburg, Sweden

5 Department of Plastic and Reconstructive Surgery, Skåne University Hospital, Malmö, Sweden [interquartile range (IQR) 57-80] and for psychosocial well-being 82 (IQR 61-100). Poor/fair results on BCCT.core were associated with $Q$-scores below median for both satisfaction with breasts [odds ratio (OR) 3.4 (confidence interval (CI) 1.7-6.8)] as well as for psychosocial wellbeing [OR 2.2 (CI 1.1-4.2)].

Conclusions A statistically significant association between BCCT.core results one year after BCT and quality of life ratings using BREAST-Q ${ }^{\mathrm{TM}}$ several years later is shown in this study. This implies that the BCCT.core may be valuable in BCT follow-up and used as a standardised instrument in the evaluation of aesthetic results.

Keywords Breast-conserving therapy - BCCT.core BREAST-Q - Aesthetic result · Health-related quality of life

\begin{tabular}{|c|c|}
\hline \multicolumn{2}{|c|}{ Abbreviations } \\
\hline BCCT.core & $\begin{array}{l}\text { Breast cancer conservative treatment. } \\
\text { cosmetic results }\end{array}$ \\
\hline $\mathrm{BCS}$ & Breast-conserving surgery \\
\hline BCT & $\begin{array}{l}\text { Breast-conserving therapy (BCS plus } \\
\text { adjuvant radiotherapy) }\end{array}$ \\
\hline BCTOS & Breast cancer treatment outcome scale \\
\hline HRQoL & Health-related quality of life \\
\hline IQR & Interquartile range \\
\hline PROM & Patient-reported outcome measure \\
\hline
\end{tabular}

\section{Introduction}

Breast cancer is the most common cancer in women in Sweden, with an annual incidence of approximately 160 per 100,000 individuals [1]. About 75\% [2] of women with an unifocal breast cancer up to three centimetres in 
diameter are treated with breast-conserving therapy (BCT), i.e., a partial mastectomy followed by adjuvant radiotherapy, which has been shown to have equal mortality rates compared to mastectomy when treating small breast tumours [3]. The great majority of patients survive treatment long term [2], making postoperative aesthetic outcome and health-related quality of life (HRQoL) important outcome measures. HRQoL can be assessed by patientreported outcome measures (PROMs). For evaluation of PROM in women undergoing breast surgery, a validated questionnaire, i.e., the BREAST-Q ${ }^{\mathrm{TM}}$ has been developed [4-10]. The BREAST- $\mathrm{Q}^{\mathrm{TM}}$ BCT module has recently been translated into Swedish.

Much research has been done to assess the aesthetic outcome after breast cancer surgery [11-14]. However, comparisons between studies are difficult since standardised instruments are lacking. A research group in Portugal (INESC porto research group), aiming to create an objective tool to evaluate breast aesthetics, has developed a software, i.e., the Breast Cancer Conservative Treatment. cosmetic results (BCCT.core). Assessing two-dimensional photographs, BCCT.core produces a rated result: excellent, good, fair, or poor aesthetic outcome, based on symmetry, skin colour, and scar appearance $[15,16]$

The aim of this study was to investigate how the postoperative aesthetic result, evaluated with the BCCT.core approximately a year after BCT, correlated with the patients' HRQoL after additional follow-up time had elapsed, using the BREAST-Q ${ }^{\mathrm{TM}}$ questionnaire.

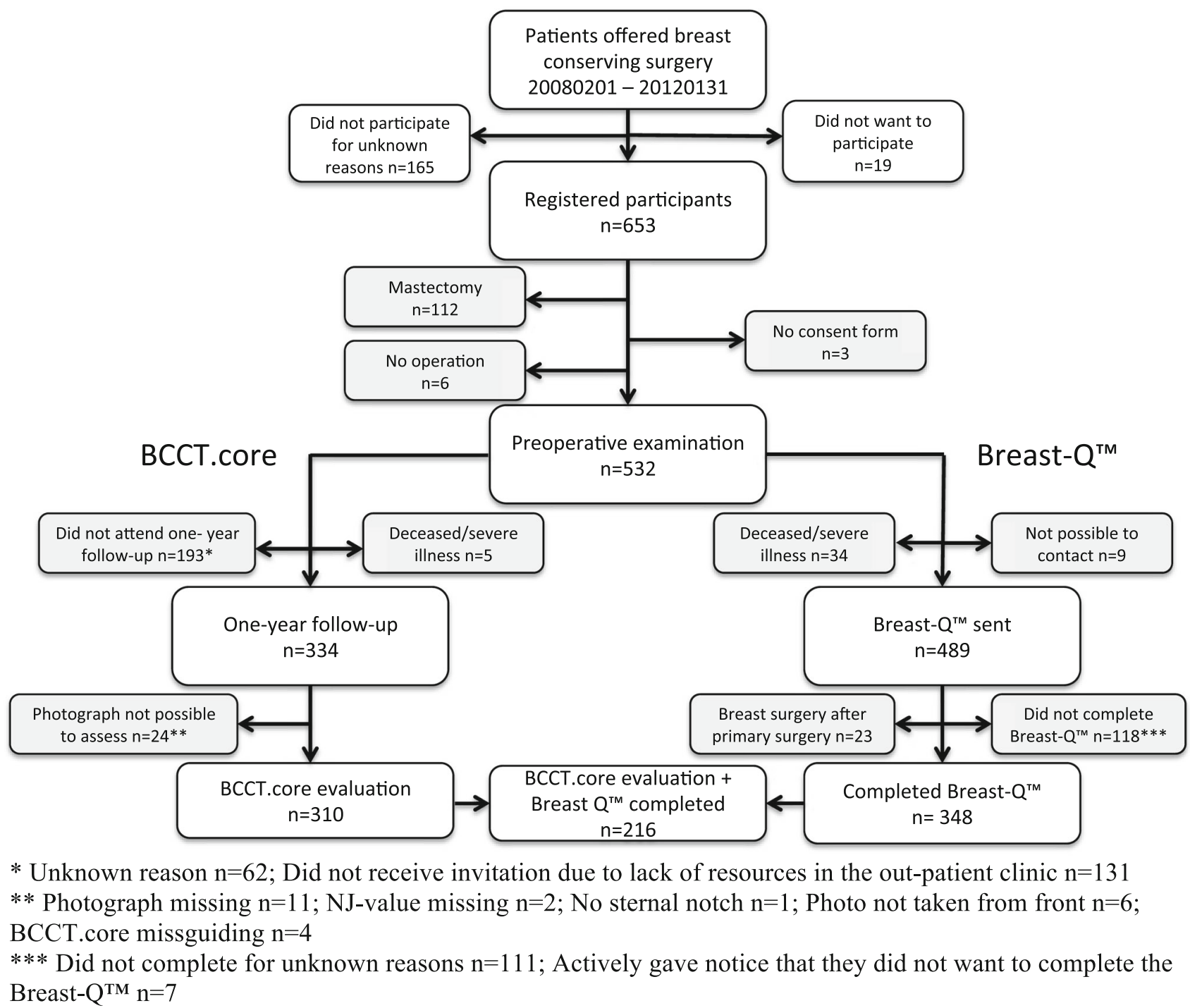

Fig. 1 Study population 


\section{Methods}

\section{Patients}

Patients who were offered BCT due to a suspected breast cancer, at Skåne University Hospital Malmö, between February 1st 2008 and January 31st 2012, were eligible for inclusion in the study. Comprehension of given information in spoken and written Swedish was warranted. The patients were usually offered BCT if the tumour was unifocal, less than four centimetres in diameter, and if the surgeon considered that the postoperative aesthetic result would be acceptable. A total of 653 patients were identified as eligible participants and were registered in the study database (Fig. 1). The material was retrospectively compared to the National Swedish Breast Cancer Registry. It was established that $78 \%$ of potential participants had been registered [17].

\section{Baseline examination}

The attending surgeon did the preoperative examination. Age at the time of surgery was registered. Weight was measured in kilograms (one decimal) and height to the closest half centimetre. Breast volume in millilitres was measured bilaterally by use of plastic cups, specially designed and previously validated [18, 19]. Nipple to jugular notch $(\mathrm{NJ})$ distance was measured bilaterally to the closest half centimetre.

\section{Surgery and adjuvant treatment}

The surgical technique used was registered by the surgeon. Mobilisation of the breast tissue from the overlying skin and pectoral fascia was routine in a "conventional" partial mastectomy, which was performed in 503 cases. Oncoplastic breast surgery techniques were registered in 29 cases. Reduction mammaplasty of the opposite breast to achieve symmetry was performed in seven cases. Five patients had bilateral tumours. Six breast surgeons performed $99 \%$ of the operations.

The sentinel node technique was routinely used for examination of nodal involvement of the axilla. If metastases were found, a completing axillary lymph node dissection was performed. Specimen weight in grams was compared to the preoperative breast volume to assess the estimated percentage of breast volume excised (EPBVE). Chemotherapy, radiotherapy, and hormonal treatment were given according to national guidelines [20]. Depending on patient age and tumour characteristics adjuvant radiotherapy was administered to the remaining breast parenchyma. Twenty-five women were enrolled in a parallel ongoing study, which evaluated oncological outcome after breastconserving surgery (BCS) without radiotherapy in women with age $>65$ treated with hormonal therapy.

\section{Follow-up}

Approximately one year after completed radiotherapy, patients were invited to follow-up. A trained nurse photographed the patients from the front with arms down (frontal projection) using a using a Nikon Coolpix S200 camera. Body weight, breast volumes, and NJ-distances were measured. During certain time periods, invitations to follow-up were not sent out as planned, due to limited resources in the out-patient clinic. This accounted for 131 of the 193 non-attending patients. The follow-up visit took place after a median of 16 months [interquartile range (IQR) 15-18; range 11-23] after the operation.

\section{BCCT.core}

The postoperative photo (frontal projection) was evaluated using the BCCT.core software. According to the BCCT.core manual, a marker is to be placed $25 \mathrm{~cm}$ down from the jugular notch to calibrate distance. Since the NJ-distance had been recorded at the same time that the patient was photographed, this calibration could be performed in retrospect. Using Gimp ${ }^{\circledR}$ software (GNU image manipulation program), a free and open source image editor on the Internet, the NJ-distance was measured in the photo, divided by the actual NJ-distance recorded at the visit, and the result was subsequently multiplied by 25 , resulting in a calibrated distance to be marked out. The photo was evaluated in the BCCT.core software, obtaining a result: excellent, good, fair, or poor. The software and the algorithms for evaluation are available in an article by Cardoso et al. [15].

\section{BREAST-Q $\mathbf{Q}^{\mathrm{TM}}$}

The BREAST- $\mathrm{Q}^{\mathrm{TM}}$ is a disease-specific validated questionnaire for evaluating PROM. It was developed by the Memorial Sloan Kettering Cancer Institute and the University of British Columbia. ${ }^{1}$ The BCT module was developed for BCS with adjuvant radiotherapy, i.e., BCT for breast cancer.

In 2015, the translation of the BCT module to Swedish was completed. The translation process followed the "linguistic validation of a patient-reported outcomes

\footnotetext{
${ }^{1}$ Copyright notice: "Memorial Sloan-Kettering Cancer Center and the University of British Columbia ${ }^{\mathrm{TM}}$ 2006, All rights reserved". Contact information and permission to use: MAPI Research Trust, Lyon, France. E-mail: PROinformation@mapi-trust.org; Internet: www.proqolid.org.
} 
measure" guidelines provided by the MAPI Research Trust. The original questionnaire (source language) was subjected to a "forward translation" by two professional translators, creating their own independent Swedish translation. These two translations were compared and combined into an accepted translation (version 1). A professional translator then subjected this version to a "backward translation" into the source language (version 2) without access to the source document. Version 2 was compared to the source document and the Swedish version (version 1) was adjusted into a final translated version (version 3). Version 3 of the pre- and postoperative questionnaire was subjected to face-validation on the appropriate patient group. The preoperative group consisted of five women scheduled for breast cancer surgery the next day. The age span of these women was 36-64 years. The postoperative group consisted of five women, age 52-68 years, previously subjected to BCT. An experienced research nurse conducted the face validation. Following some minor adjustments to version 3, the final Swedish translation was approved.

The postoperative BREAST- $\mathrm{Q}^{\mathrm{TM}}$ questionnaire was administered to 489 women by mail together with an explanatory letter and a study-specific questionnaire. Two reminders were sent by mail to those who had not returned the questionnaire. Following this, the response rate was $76 \%$. The women were asked to report when they last had surgery to either breast, and 23 women who had undergone additional breast surgery after the one-year follow-up were excluded. In all, 348 BREAST-Q ${ }^{\mathrm{TM}}$ questionnaires were available for evaluation. The BREAST-Q ${ }^{\mathrm{TM}}$ was completed with a median of 5.5 years postoperatively (range 3.7-7.9 years).

\section{Statistical methods}

The association between results of the BCCT.core and different potential determinants was analysed with cross tables and statistical significance tested using a $\chi^{2}$ test. $p$ values below 0.05 were considered statistically significant. Continuous variables among the potential determinants were categorised into subgroups.

The result from the BREAST- $\mathrm{Q}^{\mathrm{TM}}$ postoperative questionnaire was analysed according to the user instructions provided by the MAPI Research Trust. Patients who had answered less than half of the questions in a domain were excluded from analysis of that specific domain. The resulting score for each domain was converted to a $Q$-score (range 0-100) by the use of a manual scoring table, as recommended by the MAPI Research Trust.

When comparing $Q$-scores to the results of the BCCT.core, $Q$-scores were divided into four groups based on quartiles. In an additional analysis, the effect of the BCCT.core result on the result of BREAST- $\mathrm{Q}^{\mathrm{TM}}$ was investigated. To enable the use of logistic regression analysis, $Q$-scores were dichotomised with a cut-off based on the median value. Using logistic regression, odds ratios (OR) were obtained, with $95 \%$ confidence intervals (CI). The BCCT.core result was here presented both in the original four groups but also dichotomised into "excellent/good" and "fair/poor" to simplify the interpretation. The results were adjusted for age and in an additional model, for factors that in the univariate analysis showed a statistically significant association with the BCCT.core result.

Statistical analysis was performed using IBM SPSS ${ }^{\circledR}$ Statistics for Macintosh, Version 22.0. Armonk, NY: IBM Corp.

\section{Results}

Preoperative characteristics of all included patients $(n=532)$, those with BCCT.core evaluation available $(n=310)$, those with BREAST-Q ${ }^{\mathrm{TM}}$ questionnaires available $(n=348)$ and those with both $(n=216)$ are presented in Table 1 . The characteristics in the different groups are very similar.

Results of the BCCT.core were: excellent $n=49$ (15.8\%); good $n=178$ (57.4\%); fair $n=73$ (23.5\%); poor $n=10(3.2 \%)$. Associations with potential determinants

Table 1 Preoperative characteristics

\begin{tabular}{lcccc}
\hline & $\begin{array}{l}\text { Patients included } \\
(n=532)\end{array}$ & $\begin{array}{l}\text { BCCT.core evaluated } \\
(n=310)\end{array}$ & $\begin{array}{l}\text { Breast-Q } \\
(n=348)\end{array}$ & $\begin{array}{l}\text { BCCT.core and Breast-Q } Q^{\mathrm{TM}} \\
(n=216)\end{array}$ \\
\hline Age (years) & $60(51-67)^{\mathrm{a}}$ & $62(54-68)$ & $60(51-67)$ & $61(54-67)$ \\
BMI $\left(\mathrm{kg} / \mathrm{m}^{2}\right)$ & $26(23-29)$ & $25(23-29)$ & $26(23-30)$ & $25(23-29)$ \\
Breast size (ml) & $500(375-800)$ & $500(375-790)$ & $500(375-825)$ & $500(375-737.5)$ \\
$\begin{array}{l}\text { Tumour size } \\
(\mathrm{mm})\end{array}$ & $15(10-20)$ & $15(10-20)$ & $15(10-20)$ & $15(10-20)$ \\
\hline a median $(\mathrm{IQR})$ & & &
\end{tabular}


are shown in Table 2, along with $p$ values. BMI, preoperative breast size and radiotherapy each had a statistically significant association with the resulting score. Women with low BMI $(<25)$ and smaller breasts preoperatively scored better on the BCCT.core, whereas radiotherapy was associated with poorer results.

The median $Q$-score for 345 women who had answered the BREAST- $\mathrm{Q}^{\mathrm{TM}}$ postoperative questionnaire domain
"Satisfaction with breasts" was 66 (IQR 57-80; range 12-100). Regarding "psychosocial well being", the median was 82 (IQR 61-100; range 0-100). Only 207 women had answered enough of the questions in the domain "sexual well being" to be analysed. Median $Q$-score of this domain was 60 (IQR 48-79). For "adverse effects of radiation" $(n=338)$, median was 100 (IQR 89-100) and for "physical well being" $(n=339)$ it was $81(69-92)$.

Table 2 BCCT.core score in relation to potential determinants

\begin{tabular}{|c|c|c|c|c|c|}
\hline Factor & Poor & Fair & Good & Excellent & $p$ value \\
\hline \multicolumn{6}{|c|}{ Age at operation (years) } \\
\hline$<50$ & $0(0)$ & $10(13.7)$ & $29(16.3)$ & $10(20.4)$ & \multirow[t]{3}{*}{0.398} \\
\hline$\geq 50-<65$ & $4(40.0)$ & $27(37.0)$ & $82(46.1)$ & $19(38.8)$ & \\
\hline$\geq 65$ & $6(60.0)$ & $36(49.3)$ & $67(37.6)$ & $20(40.8)$ & \\
\hline \multicolumn{6}{|c|}{ BMI at operation $\left(\mathrm{kg} / \mathrm{m}^{2}\right)$} \\
\hline$<25$ & $2(20.0)$ & $24(32.9)$ & $77(43.3)$ & $29(59.2)$ & \multirow[t]{4}{*}{0.002} \\
\hline$\geq 25-<30$ & $6(60.0)$ & $22(30.1)$ & $68(38.2)$ & $9(18.4)$ & \\
\hline$\geq 30$ & $2(20.0)$ & $27(37.0)$ & $33(18.5)$ & $10(20.4)$ & \\
\hline Missing & & & & $1(2.0)$ & \\
\hline \multicolumn{6}{|c|}{ Breast size preoperatively $(\mathrm{ml})$} \\
\hline$<450$ & $1(10.0)$ & $17(23.6)$ & $57(32.6)$ & $21(43.8)$ & \multirow[t]{3}{*}{0.019} \\
\hline$\geq 450-<650$ & $5(50.0)$ & $18(25.0)$ & $62(35.4)$ & $15(31.3)$ & \\
\hline$\geq 650$ & $4(40.0)$ & $37(51.4)$ & $56(32.0)$ & $12(25.0)$ & \\
\hline \multicolumn{6}{|c|}{ Estimated percentage of breast volume excised (\%) } \\
\hline$<10$ & $2(20.0)$ & $20(27.4)$ & $52(29.2)$ & $18(36.7)$ & \multirow[t]{4}{*}{0.331} \\
\hline$\geq 10-<20$ & $4(40.0)$ & $36(49.3)$ & $92(51.7)$ & $22(44.9)$ & \\
\hline$\geq 20$ & $4(40.0)$ & $13(17.8)$ & $23(12.9)$ & $6(12.2)$ & \\
\hline Missing & $0(0)$ & $4(5.5)$ & $11(6.2)$ & $3(6.1)$ & \\
\hline \multicolumn{6}{|c|}{ Oncoplastic breast surgery } \\
\hline No & $10(100)$ & $69(94.5)$ & $165(92.7)$ & $46(93.9)$ & \multirow[t]{2}{*}{0.795} \\
\hline Yes & $0(0)$ & $4(5.5)$ & $13(7.3)$ & $3(6.1)$ & \\
\hline \multicolumn{6}{|c|}{ Axillary clearance } \\
\hline No & $9(90.0)$ & $55(75.3)$ & $147(83.1)$ & $43(89.6)$ & \multirow[t]{2}{*}{0.197} \\
\hline Yes & $1(10.0)$ & $18(24.7)$ & $30(16.9)$ & $5(10.4)$ & \\
\hline \multicolumn{6}{|l|}{ Re-excision } \\
\hline No & $9(90.0)$ & $68(93.2)$ & $166(93.3)$ & $47(95.9)$ & \multirow[t]{2}{*}{0.871} \\
\hline Yes & $1(10.0)$ & $5(6.8)$ & $12(6.7)$ & $2(4.1)$ & \\
\hline \multicolumn{6}{|l|}{ Radiotherapy } \\
\hline No & $0(0)$ & $10(13.7)$ & $21(11.8)$ & $18(36.7)$ & \multirow[t]{2}{*}{$<0.001$} \\
\hline Yes & $10(100)$ & $63(86.3)$ & $157(88.2)$ & $31(63.3)$ & \\
\hline \multicolumn{6}{|l|}{ Chemotherapy } \\
\hline No & $7(70.0)$ & $67(91.8)$ & $153(86.0)$ & $44(89.8)$ & \multirow[t]{2}{*}{0.202} \\
\hline Yes & $3(30.0)$ & $6(8.2)$ & $25(14.0)$ & $5(10.2)$ & \\
\hline \multicolumn{6}{|c|}{ Hormonal therapy } \\
\hline No & $5(50.0)$ & $28(38.4)$ & $78(43.8)$ & $19(38.8)$ & \multirow[t]{2}{*}{0.774} \\
\hline Yes & $5(50.0)$ & 45 (61.6) & $100(56.2)$ & $30(61.2)$ & \\
\hline \multicolumn{6}{|c|}{ Benign histopathology } \\
\hline No & $10(100)$ & $70(95.9)$ & $166(93.3)$ & $41(83.7)$ & \multirow[t]{2}{*}{0.052} \\
\hline Yes & $0(0)$ & $3(4.1)$ & $12(6.7)$ & $8(16.3)$ & \\
\hline
\end{tabular}


We chose to analyse BCCT.core results with the domains "satisfaction with breasts" and "psychosocial well being" since these were considered most likely to be affected by the aesthetic result and had an adequate questionnaire response rate.

In Table 3, quartiles of the $Q$-scores are related to the BCCT.core results. It can be observed that patients with a $Q$-score in the highest quartile more often had a good or excellent BCCT.core result, compared to those with a $Q$-score in the lowest quartile. In Table 4, BCCT.core results are related to $Q$-scores dichotomised with cut-off at the median. The patients with a fair/poor result on BCCT.core had lower $Q$-scores both concerning satisfaction with breasts (cut-off 66) with an OR of 3.4 (CI 1.7-6.8) and concerning psychosocial well-being (cut-off 82) with an OR of 2.2 (CI 1.1-4.2). The results remained statistically significant in the age-adjusted model. When also adjusting for the factors having a statistically significant association with result on BCCT.core in Table 2, i.e., $\mathrm{BMI}$, breast size preoperatively, and radiotherapy, the OR for satisfaction with breasts was 2.6 (CI 1.2-5.4) and for psychosocial well-being it was 2.0 (CI 1.0-4.2).

\section{Discussion}

In this study, the results of the BCCT.core were excellent in $16 \%$ of cases, good in $57 \%$, fair in $24 \%$, and poor in $3 \%$. A poor/fair result increased the risk of having $Q$-scores below median regarding satisfaction with breasts [(median 66) OR 3.4 (CI 1.7-6.8)] as well as with psychosocial wellbeing [(median 82) OR 2.2 (CI 1.1-4.2)]. The results remained statistically significant in both the adjusted models.

There are few previous studies to compare our results with, given that the BREAST- $\mathrm{Q}^{\mathrm{TM}} \mathrm{BCT}$ module is relatively new. In 2016, O'Connell et al. presented the first study using the BCT module. The study population was 200 women who had undergone unilateral $\mathrm{BCT}$ one to six years prior to the start of the study. A median $Q$-score of 68 (IQR 55-80) was reported regarding satisfaction with breasts and $82(63-100)$ regarding psychosocial well-being [21]. These results are nearly identical to our results, indicating the possibility of $Q$ score reference values to be formed.

The BCCT.core results in our study can be compared to the long-term ( 3 years) follow-up results of 356 patients,
Table $3 Q$-score (quartiles) related to BCCT.core results (dichotomized and in four groups)

\begin{tabular}{|c|c|c|c|c|}
\hline & \multicolumn{4}{|l|}{ Breast- $Q^{\mathrm{TM}}$} \\
\hline & \multicolumn{4}{|c|}{ Satisfaction with breasts } \\
\hline & $\leq 57 n(\%)$ & $58-66 n(\%)$ & $67-80 n(\%)$ & $>80 n(\%)$ \\
\hline \multicolumn{5}{|l|}{ BCCT.core result } \\
\hline Good/excellent & $33(33.7)$ & $34(44.2)$ & $52(55.3)$ & $44(57.9)$ \\
\hline Fair/poor & $23(23.5)$ & $13(16.9)$ & $10(10.6)$ & $5(6.6)$ \\
\hline Missing & $42(42.9)$ & $30(39.0)$ & $32(34.0)$ & $27(35.5)$ \\
\hline \multicolumn{5}{|l|}{ BCCT.core result } \\
\hline Excellent & $3(5.4)$ & $4(8.5)$ & $12(19.4)$ & $12(24.5)$ \\
\hline Good & $30(53.6)$ & $30(63.8)$ & $40(64.5)$ & $32(65.3)$ \\
\hline Fair & $19(33.9)$ & $13(27.7)$ & $9(14.5)$ & $4(8.2)$ \\
\hline \multirow[t]{4}{*}{ Poor } & $4(7.1)$ & $0(0)$ & $1(1.6)$ & $1(2.0)$ \\
\hline & \multicolumn{4}{|l|}{ Breast- $\mathrm{Q}^{\mathrm{TM}}$} \\
\hline & \multicolumn{4}{|c|}{ Psychosocial well-being } \\
\hline & $\leq 59 n(\%)$ & $60-82 n(\%)$ & $83-99 n(\%)$ & $100 n(\%)$ \\
\hline \multicolumn{5}{|l|}{ BCCT.core result } \\
\hline Good/excellent & $27(33.3)$ & $45(48.4)$ & $18(46.2)$ & $71(55.5)$ \\
\hline Fair/poor & $16(19.8)$ & $16(17.2)$ & $6(15.4)$ & $12(9.4)$ \\
\hline Missing & $38(46.9)$ & $32(34.4)$ & $15(38.5)$ & $45(35.2)$ \\
\hline \multicolumn{5}{|l|}{ BCCT.core result } \\
\hline Excellent & $3(7.0)$ & $8(13.1)$ & $3(12.5)$ & $17(20.5)$ \\
\hline Good & $24(55.8)$ & $37(60.7)$ & $15(62.5)$ & $54(65.1)$ \\
\hline Fair & $13(30.2)$ & $16(26.2)$ & $4(16.7)$ & $11(13.3)$ \\
\hline Poor & $3(7.0)$ & $0(0)$ & $2(8.3)$ & $1(1.2)$ \\
\hline
\end{tabular}


Table $4 Q$-score (dichotomized) in relation to BCCT.core results

\begin{tabular}{|c|c|c|c|c|c|}
\hline & \multicolumn{5}{|l|}{ Breast- $\mathrm{Q}^{\mathrm{TM}}$} \\
\hline & \multicolumn{5}{|c|}{ Satisfaction with breasts } \\
\hline & $\leq 66 n(\%)$ & $>66 n(\%)$ & $\mathrm{OR}(\mathrm{CI})$ & $\mathrm{OR}(\mathrm{CI})^{\mathrm{a}}$ & $\mathrm{OR}(\mathrm{CI})^{\mathrm{b}}$ \\
\hline \multicolumn{6}{|l|}{ BCCT.core result } \\
\hline Good/excellent & $67(65.0)$ & $96(86.5)$ & 1 & 1 & 1 \\
\hline Fair/poor & $36(35.0)$ & $15(13.5)$ & $3.4(1.7-6.8)$ & $3.4(1.7-6.9)$ & $2.6(1.2-5.4)$ \\
\hline \multicolumn{6}{|l|}{ BCCT.core result } \\
\hline Excellent & $7(6.8)$ & 24 (21.6) & 1 & 1 & 1 \\
\hline Good & $60(58.3)$ & $72(64.9)$ & $2.9(1.2-7.1)$ & $2.9(1.2-7.2)$ & $2.5(1.0-6.5)$ \\
\hline Fair & $32(31.1)$ & $13(11.7)$ & $8.4(2.9-24.4)$ & $8.6(2.9-25.0)$ & $5.9(1.9-18.5)$ \\
\hline \multirow[t]{4}{*}{ Poor } & $4(3.9)$ & $2(1.8)$ & $6.9(1.0-45.6)$ & $6.5(1.0-43.8)$ & $4.9(0.7-36.1)$ \\
\hline & \multicolumn{5}{|l|}{ Breast- $\mathrm{Q}^{\mathrm{TM}}$} \\
\hline & \multicolumn{5}{|c|}{ Psychosocial well-being } \\
\hline & $\leq 82 n(\%)$ & $>82 n(\%)$ & & & \\
\hline \multicolumn{6}{|l|}{ BCCT.core result } \\
\hline Good/excellent & $72(69.2)$ & $89(83.2)$ & 1 & 1 & 1 \\
\hline Fair/poor & $32(30.8)$ & $18(16.8)$ & $2.2(1.1-4.2)$ & $2.2(1.1-4.2)$ & $2.0(1.0-4.2)$ \\
\hline \multicolumn{6}{|l|}{ BCCT.core result } \\
\hline Excellent & $11(10.6)$ & $20(18.7)$ & 1 & 1 & 1 \\
\hline Good & $61(58.7)$ & $69(64.5)$ & $1.6(0.7-3.6)$ & $1.6(0.7-3.6)$ & $1.6(0.7-3.7)$ \\
\hline Fair & $29(27.9)$ & $15(14.0)$ & $3.5(1.3-9.2)$ & $3.4(1.3-9.1)$ & $3.3(1.2-9.6)$ \\
\hline Poor & $3(2.9)$ & $3(2.8)$ & $1.8(0.3-10.6)$ & $1.7(0.3-10.2)$ & $1.5(0.2-9.6)$ \\
\hline
\end{tabular}

who had undergone BCT, presented 2015 in a study by Hennigs et al. In their study cohort, the results of BCCT.core were excellent in 62 cases $(17.4 \%)$, good in $181(50.8 \%)$, fair in $101(28.4 \%)$, and poor in 12 cases $(3.4 \%)$, i.e., very similar to the results of our study [22]. In 2014 Haloua et al. reported BCCT.core results of excellent in 10 cases $(9 \%)$, good in $54(50 \%)$, fair in $34(31 \%)$ and poor in 11 cases $(10 \%)$ in a study cohort who had undergone BCT at least one year before the evaluation [23].

Kim et al. analysed outcome after latissimus dorsi flap reconstruction in 64 patients in a pilot study in 2015 [24]. With linear regression analysis, they could report an association between better BCCT.core results and higher $Q$ scores regarding satisfaction with breasts $\left(R^{2}=0.070\right.$; $p=0.039)$ as well as with psychosocial well-being $\left(R^{2}=0.085 ; p=0.023\right)$. In our study, we showed an association between poor/fair BCCT.core results a year after BCT and lower $Q$-scores several years later (median 5.5 years). Whether the aesthetic result has changed during this time period is not known. Some studies have shown a long-term deterioration of the aesthetic result [25, 26] especially after aggressive radiotherapy. However, these studies are based on study populations treated decades ago and might not be applicable to patients treated today with more modern radiotherapy techniques. In 2017, Soror et al. compared aesthetic outcome evaluated by a panel of observers in 114 patients treated with accelerated partial breast irradiation after 3-4 weeks postoperatively to the result after approximately 3.5 years. In their material, about $60 \%$ had the same score, $36 \%$ had better, and $4 \%$ had worse scores [27]. In a study by Heil et al., aesthetic status, evaluated by patients completing the breast cancer treatment outcome scale (BCTOS) questionnaire, did not significantly differ from shortly after surgery compared to after one year [28]. Similarly using the BCTOS, Hennigs et al. reported that patients unsatisfied with aesthetic status shortly after surgery were likely to remain unsatisfied after 2-6 years [29].

\section{Limitations}

Since the BREAST-Q ${ }^{\mathrm{TM}}$ BCT module had not been developed when our study was initiated, no preoperative assessment of quality of life by this method could be retrieved for comparison, even though it would have been valuable to have a baseline measurement.

There is the potential bias between responders and nonresponders when administering follow-up questionnaires by mail. We have tried raising the response rate by two 
reminders by mail, and have reached a percentage of $76 \%$, which we consider to be an acceptable response rate. In Table 1, baseline characteristics of the study group with BCCT.core results and completed BREAST- $\mathrm{Q}^{\mathrm{TM}}$ available can be compared to those of the entire study population and they show very similar results. We consider that the risk of any major selection bias is low.

The photographs in this study were not taken in a standardised way, i.e., with specific light setting and at a certain distance. However, in the literature published by the researchers behind BCCT.core, no such requirements are presented. The calibration of distance required was solved since NJ-distances were available. The measurement of NJdistances has been validated previously [30].

\section{Conclusion}

The results of aesthetic outcome using BCCT.core and that of HRQoL measured by the BREAST- $\mathrm{Q}^{\mathrm{TM}} \mathrm{BCT}$ module in our study resonate well with results of other recent studies. This might contribute to the development of a credible reference range for clinicians using the postoperative module to compare with.

The association shown in this study, between a poor result one year after BCT evaluated with BCCT.core and lower $Q$-scores several years later measured with BREAST- $\mathrm{Q}^{\mathrm{TM}} \mathrm{BCT}$ module strengthens the objective to use these evaluation instruments after BCT.

\begin{abstract}
Acknowledgements We would like to thank the nurses and the surgeons at the Breast Unit at Skåne University Hospital, Malmö, for their contribution to the data collection process and we especially thank Ingrid Tengrup (MD, PhD) for her contribution to the set-up of the study.
\end{abstract}

Funding This work was supported by the Gunnar Nilsson Cancer Foundation, The Ernhold Lundström Foundation, The Einar and Inga Nilsson Foundation, The Malmö University Hospital Cancer Research Fund, The Skåne University Hospital Funds and Donations, The Breast Cancer network at Lund University, and The Region Skåne (ALF). The funding sponsors had no input on the design, analysis, or writing of the paper.

\section{Compliance with ethical standards}

Conflict of interest The authors declare that they have no conflict of interest.

Ethical approval All procedures performed in studies involving human participants were in accordance with the ethical standards of the institutional and/or national research committee and with the 1964 Helsinki declaration and its later amendments or comparable ethical standards. The Ethics Committee of Lund University approved the study (Dnr 488/2007 and 230/2015).

Informed consent Informed consent was obtained from all individual participants included in the study.
Open Access This article is distributed under the terms of the Creative Commons Attribution 4.0 International License (http://crea tivecommons.org/licenses/by/4.0/), which permits unrestricted use, distribution, and reproduction in any medium, provided you give appropriate credit to the original author(s) and the source, provide a link to the Creative Commons license, and indicate if changes were made.

\section{References}

1. Socialstyrelsen Statistical Database of Cancer (2017). http:// www.socialstyrelsen.se/statistik/statistikdatabas/cancer. Accessed 14 March 2017

2. Annual Report from the National Breast Cancer Registry (2015). https://www.cancercentrum.se/globalassets/cancerdiagnoser/ brost/kvalitetsregister/nationell_brostcancer_rapport_2015-2pdf. pdf. Accessed 14 March 2017

3. Veronesi U, Cascinelli N, Mariani L, Greco M, Saccozzi R, Luini A, Aguilar M, Marubini E (2002) Twenty-year follow-up of a randomized study comparing breast-conserving surgery with radical mastectomy for early breast cancer. N Engl J Med 347(16):1227-1232

4. Pusic AL, Chen CM, Cano S, Klassen A, McCarthy C, Collins ED, Cordeiro PG (2007) Measuring quality of life in cosmetic and reconstructive breast surgery: a systematic review of patientreported outcomes instruments. Plast Reconstr Surg 120(4):823-837. doi:10.1097/01.prs.0000278162.82906.81 (Discussion 838-829)

5. Pusic AL, Klassen AF, Snell L, Cano SJ, McCarthy C, Scott A, Cemal Y, Rubin LR, Cordeiro PG (2012) Measuring and managing patient expectations for breast reconstruction: impact on quality of life and patient satisfaction. Expert Rev Pharm Outcomes Res 12(2):149-158. doi:10.1586/erp.11.105

6. Pusic AL, Reavey PL, Klassen AF, Scott A, McCarthy C, Cano SJ (2009) Measuring patient outcomes in breast augmentation: introducing the BREAST-Q augmentation module. Clin Plast Surg 36(1):23-32. doi:10.1016/j.cps.2008.07.005

7. Klassen AF, Pusic AL, Scott A, Klok J, Cano SJ (2009) Satisfaction and quality of life in women who undergo breast surgery: a qualitative study. BMC Women's Health 9:11. doi:10.1186/ 1472-6874-9-11

8. Pusic AL, Klassen AF, Scott AM, Klok JA, Cordeiro PG, Cano SJ (2009) Development of a new patient-reported outcome measure for breast surgery: the BREAST-Q. Plast Reconstr Surg 124(2):345-353. doi:10.1097/PRS.0b013e3181aee807

9. Chen CM, Cano SJ, Klassen AF, King T, McCarthy C, Cordeiro PG, Morrow M, Pusic AL (2010) Measuring quality of life in oncologic breast surgery: a systematic review of patient-reported outcome measures. Breast J 16(6):587-597. doi:10.1111/j.15244741.2010.00983.x

10. Cano SJ, Klassen AF, Scott AM, Cordeiro PG, Pusic AL (2012) The BREAST-Q: further validation in independent clinical samples. Plast Reconstr Surg 129(2):293-302. doi:10.1097/PRS. 0b013e31823aec6b

11. Taylor ME, Perez CA, Halverson KJ, Kuske RR, Philpott GW, Garcia DM, Mortimer JE, Myerson RJ, Radford D, Rush C (1995) Factors influencing cosmetic results after conservation therapy for breast cancer. Int J Radiat Oncol Biol Phys 31(4):753-764

12. Vrieling C, Collette L, Fourquet A, Hoogenraad WJ, Horiot JH, Jager JJ, Pierart M, Poortmans PM, Struikmans H, Maat B, Van Limbergen E, Bartelink H (2000) The influence of patient, tumor and treatment factors on the cosmetic results after breast-conserving therapy in the EORTC 'boost vs. no boost' trial. EORTC 
Radiotherapy and Breast Cancer Cooperative Groups. Radiother Oncol 55(3):219-232

13. Al-Ghazal SK, Blamey RW (1999) Cosmetic assessment of breast-conserving surgery for primary breast cancer. Breast 8(4): $162-168$

14. Arenas M, Sabater S, Hernandez V, Henriquez I, Ameijide A, Anglada L, Mur E, Artigues M, Lafuerza A, Borras J (2006) Cosmetic outcome of breast conservative treatment for early stage breast cancer. Clin Transl Oncol 8(5):334-338

15. Cardoso JS, Cardoso MJ (2007) Towards an intelligent medical system for the aesthetic evaluation of breast cancer conservative treatment. Artif Intell Med 40(2):115-126. doi:10.1016/j.artmed. 2007.02.007

16. Cardoso MJ, Cardoso J, Amaral N, Azevedo I, Barreau L, Bernardo M, Christie D, Costa S, Fitzal F, Fougo JL, Johansen J, Macmillan D, Mano MP, Regolo L, Rosa J, Teixeira L, Vrieling C (2007) Turning subjective into objective: the BCCT.core software for evaluation of cosmetic results in breast cancer conservative treatment. Breast 16(5):456-461. doi:10.1016/j. breast.2007.05.002

17. Dahlback C, Manjer J, Rehn M, Ringberg A (2016) Determinants for patient satisfaction regarding aesthetic outcome and skin sensitivity after breast-conserving surgery. World J Surg Oncol 14(1):303. doi:10.1186/s12957-016-1053-8

18. Hansson E, Manjer J, Ringberg A (2014) Reliability of plastic cups to measure breast volume. J Plast Surg Hand Surg 48(4):254-258. doi:10.3109/2000656X.2013.870908

19. Strombeck JO, Malm M (1986) Priority grouping in a waiting list of patients for reduction mammaplasty. Ann Plast Surg 17(6):498-502

20. Socialstyrelsen (2007) Nationella riktlinjer för bröstcancersjukvård. doi:978-91-85482-94-8

21. O’Connell RL, DiMicco R, Khabra K, O’Flynn EA, deSouza N, Roche N, Barry PA, Kirby AM, Rusby JE (2016) Initial experience of the BREAST-Q breast-conserving therapy module. Breast Cancer Res Treat 160(1):79-89. doi:10.1007/s10549-016-3966-x

22. Hennigs A, Hartmann B, Rauch G, Golatta M, Tabatabai P, Domschke C, Schott S, Schutz F, Sohn C, Heil J (2015) Longterm objective esthetic outcome after breast-conserving therapy. Breast Cancer Res Treat 153(2):345-351. doi:10.1007/s10549015-3540-y

23. Haloua MH, Krekel NM, Jacobs GJ, Zonderhuis B, Bouman MB, Buncamper ME, Niessen FB, Winters HA, Terwee C, Meijer S, van den Tol MP (2014) Cosmetic outcome assessment following breast-conserving therapy: a comparison between BCCT.core software and panel evaluation. Int J Breast Cancer 2014:716860. doi: $10.1155 / 2014 / 716860$

24. Kim KD, Kim Z, Kuk JC, Jeong J, Choi KS, Hur SM, Jeong GA, Chung JC, Cho GS, Shin EJ, Kim HC, Kang SG, Lee MH, Lim CW (2016) Long-term results of oncoplastic breast surgery with latissimus dorsi flap reconstruction: a pilot study of the objective cosmetic results and patient reported outcome. Ann Surg Treat Res 90(3):117-123. doi:10.4174/astr.2016.90.3.117

25. Immink JM, Putter H, Bartelink H, Cardoso JS, Cardoso MJ, van der Hulst-Vijgen MH, Noordijk EM, Poortmans PM, Rodenhuis CC, Struikmans H (2012) Long-term cosmetic changes after breast-conserving treatment of patients with stage I-II breast cancer and included in the EORTC 'boost versus no boost' trial. Ann Oncol 23(10):2591-2598. doi:10.1093/annonc/ mds066

26. Johansen J, Overgaard J, Rose C, Engelholm SA, Gadeberg CC, Kjaer M, Kamby C, Juul-Christensen J, Blichert-Toft M, Overgaard M (2002) Cosmetic outcome and breast morbidity in breast-conserving treatment-results from the Danish DBCG$82 \mathrm{TM}$ national randomized trial in breast cancer. Acta Oncol 41(4):369-380

27. Soror T, Kovacs G, Seibold N, Melchert C, Baumann K, Wenzel E, Stojanovic-Rundic S (2017) Cosmetic changes following surgery and accelerated partial breast irradiation using HDR interstitial brachytherapy: evaluation by a multidisciplinary/multigender committee. Strahlenther Onkol. doi:10.1007/ s00066-016-1093-6

28. Heil J, Czink E, Golatta M, Schott S, Hof H, Jenetzky E, Blumenstein M, Maleika A, Rauch G, Sohn C (2011) Change of aesthetic and functional outcome over time and their relationship to quality of life after breast conserving therapy. Eur J Surg Oncol 37(2):116-121. doi:10.1016/j.ejso.2010.11.007

29. Hennigs A, Biehl H, Rauch G, Golatta M, Tabatabai P, Domschke C, Schott S, Wallwiener M, Schutz F, Sohn C, Heil J (2016) Change of patient-reported aesthetic outcome over time and identification of factors characterizing poor aesthetic outcome after breast-conserving therapy: long-term results of a prospective cohort study. Ann Surg Oncol 23(5):1744-1751. doi:10.1245/s10434-015-4943-Z

30. Hansson E, Manjer J, Ringberg A (2014) Inter-observer reliability of clinical measurement of suprasternal notch-nipple distance and breast ptosis. Indian J Plast Surg 47(1):61-64. doi:10. 4103/0970-0358.129625 